\title{
NEW PHOSPHORUS CONTAINING BIS-SULFONE LIGANDS
}

\author{
NOÉMI DEAK ${ }^{\mathrm{a}, \mathrm{b}}$, SONIA MALLET-LADEIRA ${ }^{\mathrm{c}}$, \\ LUMINITA SILAGHI-DUMITRESCU ${ }^{a}$, DAVID MADEC ${ }^{\text {b* }}$, \\ GABRIELA NEMES*a
}

\begin{abstract}
Derivatives of bis-sulfone 1,3-bis $\left\{(p\right.$-tolyl $\left.) \mathrm{SO}_{2}\right\}-5$-tertbutylbenzene 1, containing $P(I I I)$ and $P(V)$ were obtained and characterized in solution by multinuclear NMR spectroscopy. For two of the compounds $\left(\left[2,6-\left\{\left(p \text {-tolyl) } \mathrm{SO}_{2}\right\}_{2} 4-t-\mathrm{Bu}_{-} \mathrm{C}_{6} \mathrm{H}_{2}\right] \mathrm{PCl}_{2} \quad 2\right.\right.$ and $\left[2,6-\left\{\left(p \text {-tolyl) } \mathrm{SO}_{2}\right\}_{2} 4-t-\mathrm{Bu}-\right.\right.$ $\left.\left.\mathrm{C}_{6} \mathrm{H}_{2}\right] \mathrm{P}(\mathrm{O})(\mathrm{H}) \mathrm{OEt}\right) 4$ the crystal and molecular structures in solid state were also determined by single crystal $\mathrm{X}$-ray diffraction.
\end{abstract}

Keywords: bis-sulfone, phosphorus derivatives, dichlorophosphine

\section{INTRODUCTION}

The study of phosphorus containing organic and organometallic derivatives has been a topic of interest for a long time, continuously expanding with numerous interesting results surfacing regularly. In the last decades, the chemistry of phosphines and low valent phosphorus containing compounds also came in focus. In the case of all these species the organic moieties play a very important role in the stabilization and the particular properties. Several types of ligands used to obtain low valent phosphorus derivatives are described in the literature,[1-4] like bulky organic groups (Mes, Mes ${ }^{*}$, Tip, etc), $[1,5]$ or ligands containing electron donating heteroatoms $(\mathrm{N}, \mathrm{O}$, etc).[3] The synergic effect of both the bulkiness of the ligand and its electron donating properties was also proven several times.[1,2,5,6].

a Universitatea Babeş-Bolyai, Facultatea de Chimie şi Inginerie Chimică, str. Arany Janos, nr. 11, RO-400028, Cluj-Napoca, Romania.

b Université de Toulouse, UPS, LHFA, 118 Route de Narbonne, F-31062 Toulouse, France, CNRS, LHFA, UMR 5069, F-31062 Toulouse Cedex 9, France.

c Institut de Chimie de Toulouse, FR2599, Université Paul Sabatier, UPS, 118 Route de Narbonne, F-31062 Toulouse Cedex 9, France.

*Corresponding: gabriela.nemes@ubbcluj.ro,madec@chimie.ups-tlse.fr 
Since the stabilization of the first species containing low valent phosphorus atoms [7-9] the chemistry of these derivatives experienced a great development, becoming a versatile field of study. A large number of studies were reported over the years on the stability, reactivity and applications of $\mathrm{P}(\mathrm{III})$ containing derivatives, where the importance of these compounds was highlighted for their role as ligands in organometallic chemistry $[1,3,10,16]$, in catalytic processes,[3] or compounds containing p-block elements.[5,6] The investigation of some derivatives containing phosphaalkenyl $-\mathrm{P}=\mathrm{C}<$ moieties, their synthesis, characterisation and applications in organometallic and coordinative compounds, represents one of our research interests. [6,10-15]

In this study we investigated the connecting behaviour of the bissulfone 1,3-bis\{(4-methylphenyl)sulfonyl\}-5-tert-butylbenzene $\mathbf{1}$ as a ligand towards phosphorus tri-chloride $\mathrm{PCl}_{3}$ in order to obtain new derivatives that can be used as building blocks in today's chemistry. The importance of bissulfone as ligands was recently highlighted as they function as pincer-type ligands for the stabilization of metallylenes and have an important effect in their reactivity.[17-19]

\section{RESULTS AND DISCUSIONS}

Based on the good results obtained with the bis-sulfone 1 in the stabilization of low valent group 14 elements and their reactivity,[18,19] the synthesis of phosphorus containing derivatives was also realised. A new dichlorophosphine was obtained with bis-sulfone 1, as shown in Scheme 1, using a slightly modified method from literature.[7,20,21]

Tri-chlorophosphine was added at low temperature to the carbanion of the bis-sulfone 1, obtained according to previously described methods.[18]

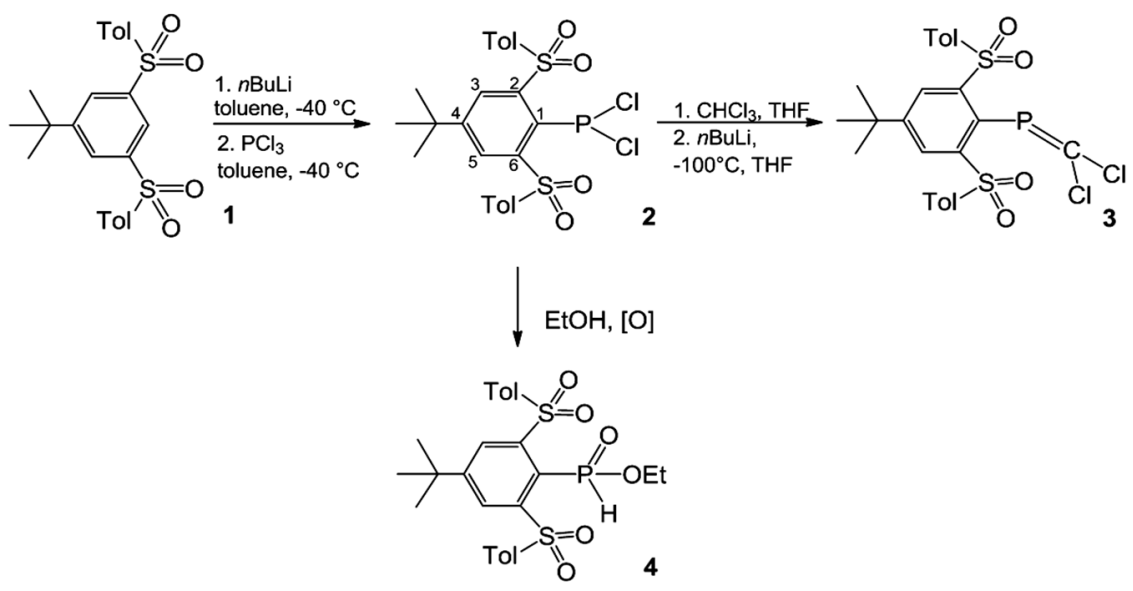

Scheme 1. Synthesis of phosphorus containing derivatives 
The new (1,3-bis\{(4-methylphenyl)sulfonyl\}-5-tert-butylphenyl)dichlorophosphine 2 was characterized in solution by NMR spectroscopy. The singlet signal in the ${ }^{31} \mathrm{P}$ NMR spectrum at $139 \mathrm{ppm}\left(\mathrm{C}_{6} \mathrm{D}_{6}\right)$ confirms the formation of derivative 2, the value of the chemical shift being in the range of chemical shifts characteristic for organo-dichlorophosphines.[22,23] In the ${ }^{1} \mathrm{H}$ NMR spectrum of compound 2 the disappearance of the multiplet signal at $8.90 \mathrm{ppm}\left(\mathrm{C}_{6} \mathrm{D}_{6},{ }^{4} \mathrm{~J}_{H H}=1.64 \mathrm{~Hz}\right)$, assigned for $\mathrm{H} 1$ of bis-sulfone 1 , can be observed, that confirms the connection of the $-\mathrm{PCl}_{2}$ fragment to the $\mathrm{C} 1$ atom (see Scheme 1). The downfield shift of the meta protons $\mathrm{H} 3$ and $\mathrm{H} 5$ on the central aromatic ring from $8.25 \mathrm{ppm}$ (in bis-sulfone $1, \mathrm{C}_{6} \mathrm{D}_{6}, \mathrm{~d},{ }^{4} \mathrm{~J}_{H H}=1.64 \mathrm{~Hz}$ ) to $8.47 \mathrm{ppm}\left(\mathrm{C}_{6} \mathrm{D}_{6}, \mathrm{~d}^{4}{ }^{4} \mathrm{~J}_{\mathrm{HH}}=1.74 \mathrm{~Hz}\right)$ also suggests the formation of the new compound. The signal for the $\mathrm{C} 1$ atom in the ${ }^{13} \mathrm{C}$ NMR spectrum of compound 2 appears at 137.3 as a doublet $\left({ }^{1} J_{C-P}=104.3 \mathrm{~Hz}\right)$, because of the bonding with the phosphorus atom, with a downfield shift from $124.6 \mathrm{ppm}$ for bis-sulfone $\mathbf{1}$, characteristic shift and coupling constant for such derivatives.[22,24]

The structure of the bis-sulfone-dichlorophosphine $\mathbf{2}$ was confirmed in solid state by single crystal X-ray diffraction; the molecular structure together with some important geometrical parameters is presented in Figure 1.

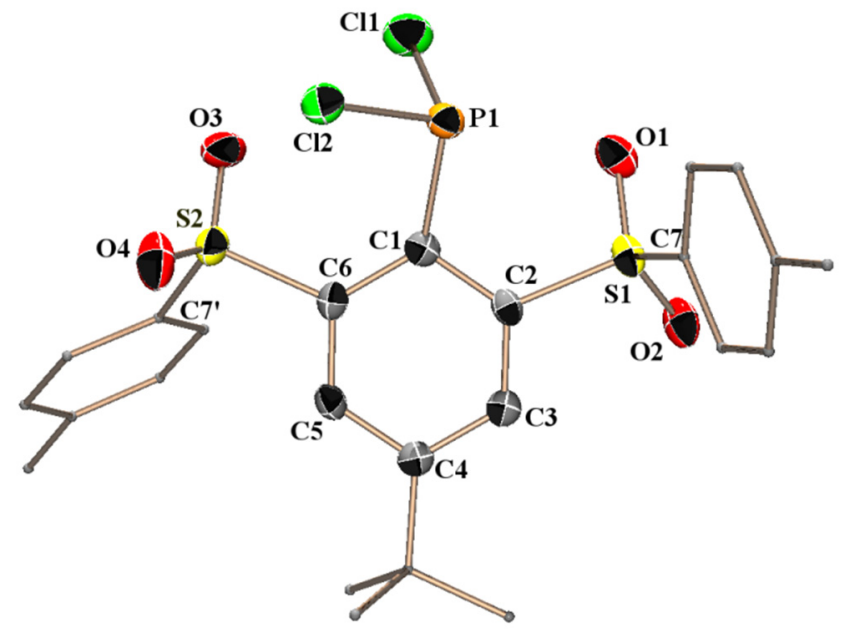

Figure 1. Molecular structure of compound 2 the solid state (50\% probability level for the thermal ellipsoids). For clarity, hydrogen atoms are omitted, tolyl and t-butyl groups are simplified. Selected bond distances $[\AA]$ and bond angles [deg]: S1-O1

1.441(3), S1-O2 1.435(3), S2-O3 1.434(3), S2-O4 1.432(3), P1-C1 1.859(3), Cl1-P1 2.050(1), Cl2-P1 2.057(1), C1-P1-Cl1 104.37(11), C1-P1-Cl2 99.57(11), Cl1-P1-Cl2 102.80(6), C6-S2-C7' 102.91(16), C2-S1-C7 106.64(15), P1-C1-C2 115.1(2), P1-C1-C6 129.1(3) 
The solid state molecular structure of compound 2 shows that the phosphorus atom adopts a pseudo-tetrahedral geometry, considering the lone pair of electrons, with the angles C1-P1-Cl1 of $104.37(11)^{\circ}, \mathrm{C} 1-\mathrm{P} 1-\mathrm{Cl} 2$ of $99.57(11)^{\circ}$ and $\mathrm{Cl} 1-\mathrm{P} 1-\mathrm{Cl} 2$ of $102.80(6)^{\circ}$. The C1-P1 bond length of $1.859(3) \AA$ and $\mathrm{P}-\mathrm{Cl}$ bond lengths of $2.050(1)$ and 2.057(1) $\AA$, are close to values found in the literature for other organo-dichlorophosphines.[20,25] The tolyl groups are situated on opposite sides of the central aromatic ring; the $S=O$ bonds are close to values observed in the case of the previously reported metallylenes with bis-sulfone ligands.[17-19] The O1-P1 distance in the dichlorophosphine 2 is of 2.754(3) $\AA$, value between the sum of the covalent radii $(1.73 \AA)[26]$ and the sum of the van der Waals radii $(3.38 \AA),[27,28]$ while the O3-P1 distance of 3.367(3) $\AA$ is almost equal to the sum of the van der Waals radii $(3.38 \AA$ ). $[27,28]$ The orientation of the sulfonyl groups (the 01, O3) and the phosphorus atom does not make possible an interaction, moreover, in the case of the phosphorus(III) atom, the presence of the lone pair of electron could lead to repulsions with the lone pair of electron on the oxygen atom. However, the bulkiness of the bis-sulfone ligand 1 makes possible the stabilization of the dichlorophosphine 2 . It is to note, that in the literature there are only a few examples for phosphines stabilized by pincer ligands.[21,29-32]

The bis-sulfone-dichlorophosphine 2 was also used as precursor in the synthesis of the (1,3-bis\{(4-methylphenyl)sulfonyl\}-5-tert-butylphenyl)dichlorophosphaalkene 3 . The formation of compound 3 was evidenced in solution by NMR spectroscopy, mainly through the ${ }^{31} \mathrm{P} N M R$, where the presence of a singlet signal at a the chemical shift $201.6 \mathrm{ppm}$, downfield shifted compared to the dichlorophosphine 2, is characteristic for derivatives containing the $-\mathrm{P}=\mathrm{C}<$ moiety. $[3,8,10-12,33]$ The ${ }^{1} \mathrm{H}$ and ${ }^{13} \mathrm{C}$ NMR spectra also confirm the formation of the expected compound 3, data are presented in experimental part. The dichlorophosphaalkene $\mathbf{3}$ is stable under inert atmosphere, and presents low stability at air, after a few days decomposition can be observed with the formation of the bis-sulfone ligand 1 .

The reactivity of the derivative 2 was also tested in the presence of ethanol and oxygen, the oxidation state of phosphorus atom switch from $P(I I I)$ to $P(V)$, together with the substitution of the chlorine atoms, the formation of ethyl(1,3-bis\{(4-methylphenyl)sulfonyl\}-5-tert-butylphenyl)phosphinate 4 was observed, as shown in Scheme 1.

The ${ }^{31} \mathrm{P}$ NMR spectra of derivative 4 exhibits a doublet signal at 12.60 ppm $\left({ }^{1} J_{P H}=615.4 \mathrm{~Hz}\right)$, with an upfield shift compared to dichlorophosphine 2 (139 ppm), found in the characteristic region for $P(V)$ phosphorus atom containing derivatives.[10,13,22] The coupling constant of $615 \mathrm{~Hz}$ suggests the presence of a hydrogen atom linked to the phosphorus atom.[22] In the ${ }^{1} \mathrm{H}$ NMR spectrum of compound 4 slight downfield shifts can be observed for 
the signals for the methyl and tert-butyl group and the aromatic protons of the bis-sulfone ligand compared to the compound 2. At $1.11 \mathrm{ppm}$ a triplet and at 4.13-4.35 ppm multiplet signals can be seen for the ethoxy group linked to the phosphorus atom.

Single crystals, suitable for X-ray analysis, were obtained and the molecular structure of compound $\mathbf{4}$ in solid state is presented in Figure 2 as well as some representative geometrical parameters.

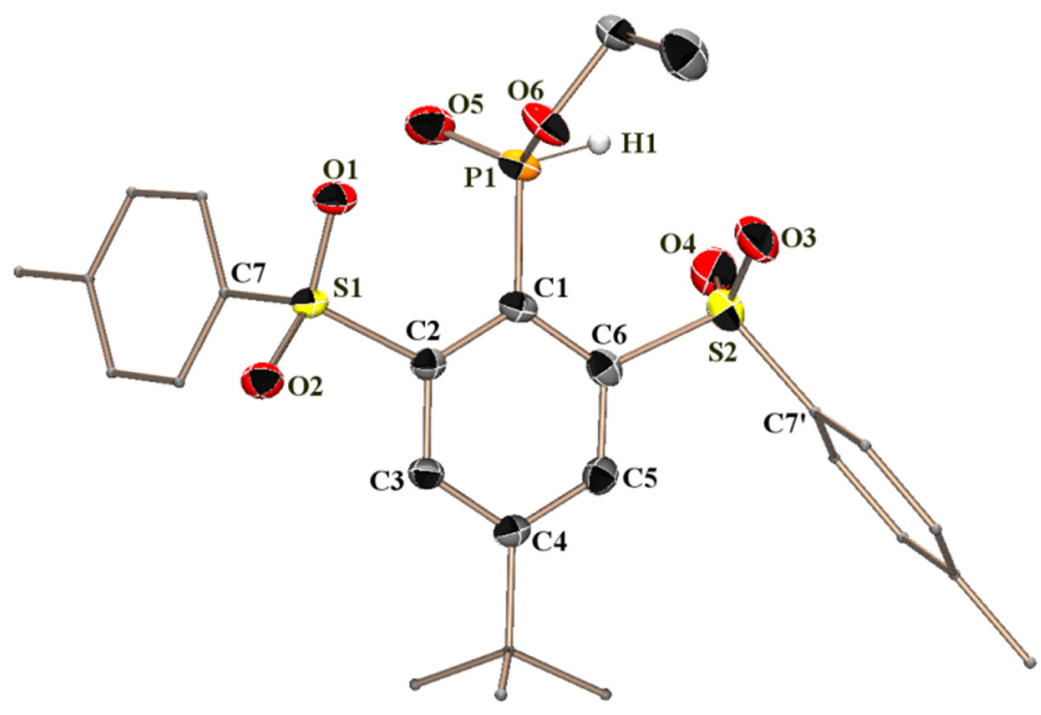

Figure 2. Molecular structure of compound 4 the solid state (50\% probability level for the thermal ellipsoids). For clarity, hydrogen atoms are omitted, tolyl and t-butyl groups are simplified. Selected bond distances $[\AA]$ and bond angles [deg]: S1-O1 1.434(1), S1-O2 1.442(1), S2-O3 1.439(1), S2-O4 1.438(1), P1-C1 1.828 (1), P1O5 1.458(1), P1-O6 1.572(1), P1-H1 1.295(18), C1-P1-O5 113.55(6), C1-P1-O6 102.53(6), C1-P1-H1 106.9(8), P1-C1-C2 123.15(10), P1-C1-C6 121.67(10).

The solid state molecular structure of compound $\mathbf{4}$ shows a similar geometrical arrangement to derivative 2. The tolyl groups are situated on opposite sides of the central aromatic ring. The O1-P1 distance is of 3.195(1) $\AA$, the O3-P1 is 2.924(1) $\AA$, values between the sum of the covalent radii $(1.73 \AA)[26]$ and the sum of the van der Waals radii $(3.38 \AA) .[27,28]$ The P$\mathrm{O} 5$ and $\mathrm{P}-\mathrm{O} 6$ distances are in the range of values found in the literature for $\mathrm{P}=\mathrm{O}$ bonds. [35]

Compound $\mathbf{4}$ is stable in the presence of moisture and oxygen. 


\section{CONCLUSIONS}

The synthesis and characterization of three new organophosphorus derivatives containing bis-sulfone ligand 1 is presented. All compounds were characterized in solution by multinuclear NMR spectroscopy; for compounds $\mathbf{2}$ and $\mathbf{4}$ the solid state molecular structure was also determined by single crystal X-ray diffraction.

The $P(I I I)$ containing derivatives show good stability under inert atmosphere of argon, while the $\mathrm{P}(\mathrm{V})$ containing derivative proved to be stable under air too.

The newly obtained organophosphorus derivatives are good candidates as precursors for organometallic compounds because of the stability of these derivatives under controlled atmosphere and the existence of multiple connecting points: lone pair of electrons of the phosphorus atom in compound 2, $\mathrm{P}=\mathrm{C}$ double bond in compound 3, oxygen atom of the $\mathrm{P}=\mathrm{O}$ bond in compound 4 and the oxygen atoms of the bis-sulfone ligand in all the cases.

\section{EXPERIMENTAL SECTION}

All syntheses were realized under dry and oxygen free argon atmosphere by using Schlenk-line and glove-box techniques; all solvents were purified using MBRAUN SBS-800 purification system. Bis-sulfone 1 was prepared according to literature procedures.[18] The NMR spectra were recorded with a Bruker Avance II $300 \mathrm{MHz}$ apparatus: ${ }^{1} \mathrm{H}\left(300.13 \mathrm{MHz}\right.$, reference TMS), ${ }^{13} \mathrm{C}(75.48$ $\mathrm{MHz}$, reference TMS), ${ }^{31} \mathrm{P}\left(121.51 \mathrm{MHz}\right.$, reference $\left.\mathrm{H}_{3} \mathrm{PO}_{4}\right)$ at $298 \mathrm{~K}$ and Bruker Avance $400 \mathrm{MHz}$ apparatus: ${ }^{1} \mathrm{H}(400.13 \mathrm{MHz}$, reference TMS $),{ }^{13} \mathrm{C}(100.61$ $\mathrm{MHz}$, reference TMS $),{ }^{31} \mathrm{P}\left(161.92 \mathrm{MHz}\right.$, reference $\left.\mathrm{H}_{3} \mathrm{PO}_{4}\right)$ at $298 \mathrm{~K}$. The signals in the ${ }^{1} \mathrm{H}$ and ${ }^{13} \mathrm{C}$ NMR spectra were assigned by COSY $\left({ }^{1} \mathrm{H}\right), \mathrm{HSQC}\left({ }^{1} \mathrm{H}-{ }^{13} \mathrm{C}\right)$, and $\mathrm{HMBC}\left({ }^{1} \mathrm{H}-{ }^{13} \mathrm{C}\right)$ experiments. The X-ray data were collected at $193(2) \mathrm{K}$ on a Bruker - AXS PHOTON100 D8 VENTURE diffractometer using MoKa radiation (wavelength $=0.71073 \AA$ ). Phi- and omega- scans were used. The data were integrated with SAINT[36] and an empirical absorption correction with SADABS[36] was applied. The structures were solved by direct methods with SHELXS-97[37] or by intrinsic phasing method (SHELXT)[38] and refined using a least-squares method on $\mathrm{F}^{2}$.[37] All non-H atoms were refined with anisotropic displacement parameters. CCDC 1587350 (2), CCDC 1587350 (4) contain the supplementary crystallographic data for this paper. These data can be obtained free of charge from The Cambridge Crystallographic Data Centre via www.ccdc.cam.ac.uk/data_request/cif. 


\section{Synthesis of compound 2}

To a solution of bis-sulfone 1[18] (300 $\mathrm{mg}, 0.678 \mathrm{mmol})$ in $12 \mathrm{~mL}$ of toluene cooled to $-40^{\circ} \mathrm{C}, n$-butyl lithium $(0.44 \mathrm{~mL}, 0.711 \mathrm{mmol}, 1.6 \mathrm{M}$ in hexane) was added dropwise. The deep red solution was stirred 20 minutes at this temperature then was added over a solution of freshly distilled $\mathrm{PCl}_{3}(0.118 \mathrm{~mL}$, $1.356 \mathrm{mmol}, 2 \mathrm{eq}$ ) in $2 \mathrm{~mL}$ of toluene at $-40^{\circ} \mathrm{C}$. The dark red reaction mixture slowly turned white while it was allowed to warm to room temperature then it was stirred for 18 hours. After the evaporation of the volatiles, the solid was extracted with $\mathrm{Et}_{2} \mathrm{O}$ and the lithium salts were eliminated by centrifugation in toluene. The compound was obtained as a white powder $(185 \mathrm{mg}$, yield $=50 \%)$. Colourless crystals suitable for X-ray analysis were obtained in toluene solution.

${ }^{1} \mathrm{H}$ NMR $\left(\mathrm{C}_{6} \mathrm{D}_{6}\right) \delta=0.86(\mathrm{~s}, 9 \mathrm{H}, t-B u), 1.78(\mathrm{~s}, 6 \mathrm{H}, \mathrm{Me}), 6.67(\mathrm{~d}, 4 \mathrm{H}$, ${ }^{3} J_{H H}=7.97 \mathrm{~Hz}, m-\mathrm{CH}$ Tol), $7.78\left(\mathrm{~d}, 4 \mathrm{H},{ }^{3} \mathrm{~J}_{H H}=8.17 \mathrm{~Hz}, o-\mathrm{CH} \mathrm{Tol}\right), 8.47(\mathrm{~d}, 2 \mathrm{H}$, $\left.{ }^{4} J_{H H}=1.74 \mathrm{~Hz}, m-\mathrm{CH} \mathrm{Ph}\right)$.

${ }^{13} \mathrm{C}$ NMR $\left(\mathrm{C}_{6} \mathrm{D}_{6}\right) \delta=21.2(\mathrm{Me}), 30.1(t-\mathrm{Bu}), 35.3(\mathrm{C} t-\mathrm{Bu}), 128.3\left(\mathrm{~d}, J_{\mathrm{C}-\mathrm{P}}=\right.$ $4.47 \mathrm{~Hz}, o-\mathrm{CH}$ Tol), $130.0(m-\mathrm{CH}$ Tol$), 132.2(m-\mathrm{CH} \mathrm{Ph}), 137.3\left(\mathrm{~d},{ }^{1} \mathrm{~J}_{\mathrm{C}-\mathrm{P}}=\right.$ 104.3 Hz, C1), 140.1 (ipso-Tol), 144.5 (p-Tol), 149.0 (d, J J-P $=22.7 \mathrm{~Hz}, C 2$, C6) $157.1(C 4)$.

\section{${ }^{31} \mathbf{P}$ NMR $\left(\mathbf{C}_{6} \mathbf{D}_{6}\right) \delta=139.1$} Scheme 1.

Note: The numbering for carbon atoms in all compounds is according to

\section{Synthesis of compound 3}

To a solution of bis-sulfone 1 (300 $\mathrm{mg}, 0.678 \mathrm{mmol})$ in $12 \mathrm{~mL}$ of toluene cooled to $-40^{\circ} \mathrm{C}$, n-butyl lithium $(0.44 \mathrm{~mL}, 0.711 \mathrm{mmol}, 1.6 \mathrm{M}$ in hexane) was added dropwise. The deep red solution was stirred 20 minutes at this temperature then was added over a solution of freshly distilled $\mathrm{PCl}_{3}(0.118 \mathrm{~mL}$, $1.356 \mathrm{mmol}, 2 \mathrm{eq}$ ) in $2 \mathrm{~mL}$ of toluene at $-40^{\circ} \mathrm{C}$. The dark red reaction mixture slowly turned white while it was allowed to warm to room temperature then it was stirred for 18 hours. All volatiles were evaporated, the white solid was solubilized in $12 \mathrm{~mL}$ of THF and freshly distilled $\mathrm{CHCl}_{3}(55 \mu \mathrm{L}, 0.678 \mathrm{mmol})$ was added to this solution. The mixture was cooled down to $-100^{\circ} \mathrm{C}$ and $n$ BuLi (0.89 mL, $1.42 \mathrm{mmol}$, 2eq, 1.6 $\mathrm{M}$ in hexane) was added dropwise. The red reaction mixture was allowed to warm to room temperature, and slowly became transparent. The mixture was stirred 18 hours at room temperature. After evaporating all volatiles the compound was washed with pentane and obtained as a white solid.

${ }^{1} \mathrm{H} \mathrm{NMR}\left(\mathrm{CDCl}_{3}\right) \delta=1.46(\mathrm{~s}, 9 \mathrm{H}, t-B u), 2.37(\mathrm{~s}, 6 \mathrm{H}, \mathrm{Me}), 7.26(\mathrm{~d}, 4 \mathrm{H}, \mathrm{J}=$ $8.08 \mathrm{~Hz}, m-\mathrm{CH}$ Tol), 8.54 (s, 4H, $m-\mathrm{CH} \mathrm{Ph}), 7.71(\mathrm{~d}, 2 \mathrm{H}, J=8.31 \mathrm{~Hz}, o-\mathrm{CH}$ Tol). 
${ }^{13} \mathrm{C} \mathrm{NMR}\left(\mathrm{CDCl}_{3}\right) \delta=21.8(\mathrm{Me}), 31.1(t-\mathrm{Bu}), 35.9(\mathrm{C} t-\mathrm{Bu}), 128.9(0-$ Tol), 129.9 ( $m$-Tol), 131.7 ( $m$-CH Ph), 137.0 (ipso-Tol and C2, C6), 136.3 and $144.9(p-\mathrm{Tol}), 146.3\left(\mathrm{~d}, J_{C-P}=3.06 \mathrm{~Hz}, C 1\right), 156.0(C 4), C=\mathrm{P}$ not seen.

${ }^{31} \mathrm{P}$ NMR $\left(\mathbf{C}_{6} \mathrm{D}_{6}\right) \delta=201.6$

\section{Characterization of compound 4}

To a solution of dichlorophosphine 2 in $\mathrm{C}_{6} \mathrm{D}_{6}, 10 \mu \mathrm{L}$ distilled EtOH was added. Transparent crystals were obtained in $\mathrm{C}_{6} \mathrm{D}_{6}$ and separated through filtration .

${ }^{1} \mathrm{H}$ NMR $\left(\mathrm{C}_{6} \mathrm{D}_{6}\right) \delta=0.94(\mathrm{~s}, 9 \mathrm{H}, t-\mathrm{Bu}), 1.76(\mathrm{~s}, 6 \mathrm{H}, \mathrm{Me}), 1.11$, (t, 3H, $\left.{ }^{3} J_{H H}=6.96 \mathrm{~Hz}-\mathrm{O}-\mathrm{CH}_{2}-\mathrm{CH}_{3}\right), 4.13$ and $4.35\left(\mathrm{~m}, 2 \mathrm{H},-\mathrm{O}-\mathrm{CH}_{2}-\mathrm{CH}_{3}\right) 6.71(\mathrm{~d}$, $4 \mathrm{H},{ }^{4} J_{H H}=7.90 \mathrm{~Hz}, m-\mathrm{CH}$ Tol), $8.02\left(\mathrm{~d}, 4 \mathrm{H},{ }^{4} \mathrm{~J}_{\mathrm{HH}}=7.82 \mathrm{~Hz}, \mathrm{o}-\mathrm{CH} \mathrm{Tol}\right), 8.89$ (d, $\left.2 \mathrm{H},{ }^{1} \mathrm{~J}_{\mathrm{HH}}=2.62 \mathrm{~Hz}, m-\mathrm{CH} \mathrm{Ph}\right)$.

$$
\begin{aligned}
& { }^{31} \mathbf{P}\left(\mathbf{C}_{6} \mathbf{D}_{6}\right) \delta=12.6\left(\mathrm{~d},{ }^{1} J_{P-H}=615.4 \mathrm{~Hz}\right) \\
& { }^{31} \mathbf{P}\{\mathrm{H}\}\left(\mathbf{C}_{6} \mathbf{D}_{6}\right) \delta=12.6
\end{aligned}
$$

\section{ACKNOWLEDGEMENTS}

This work was supported by the Babeș-Bolyai University of Cluj-Napoca, by a grant of Ministery of Research and Innovation, CNCS - UEFISCDI, project number PN-III-P4-ID-PCE-2016-0351, within PNCDI III, by the Centre National de la Recherche Scientifique (CNRS) and the Université de Toulouse (UPS).

\section{REFERENCES}

1. J.T. Fleming and L. J. Higham, Coordination Chemistry Reviews, 2015, 297298, 127.

2. J.I. Bates, J. Dugal-Tessier and D.P. Gates, Dalton Transactions, 2010, 39, 3151.

3. P.W.N.M. van Leeuwen and P.C.J. Kamer, Phosphorus(III) Ligands in Homogeneous Catalysis: Design and Synthesis, John Wiley \& Sons, Ltd, Chichester, UK, 2012.

4. D.W. Allen, D. Loakes and J.C. Tebby, Eds., Organophosphorus Chemistry, Royal Society of Chemistry, Cambridge, 2017, vol. 46.

5. M. Yoshifuji, European Journal of Inorganic Chemistry, 2016, 2016, 607.

6. J. Escudié and G. Nemeş, Comptes Rendus Chimie, 2010, 13, 954.

7. M. Yoshifuji, I. Shima, N. Inamoto, K. Hirotsu and T. Higuchi, Journal of the American Chemical Society, 1981, 103, 4587. 
8. S.J. Goede and F. Bickelhaupt, Chemische Berichte, 1991, 124, 2677.

9. T.C. Klebach, R. Lourens and F. Bickelhaupt, Journal of the American Chemical Society, 1978, 100, 4886.

10. R. Septelean, G. Nemes, J. Escudié, I. Silaghi-Dumitrescu, H. Ranaivonjatovo, P. Petrar, H. Gornitzka, L. Silaghi-Dumitrescu and N. Saffon, European Journal of Inorganic Chemistry, 2009, 2009, 628.

11. D. Matioszek, T.-G. Kocsor, A. Castel, G. Nemes, J. Escudié and N. Saffon, Chemical Communications, 2012, 48, 3629.

12. P.M. Petrar, R. Şeptelean, N. Deak, H. Gornitzka and G. Nemeş, Journal of Organometallic Chemistry, 2015, 787, 14.

13. R. Septelean, H. Ranaivonjatovo, G. Nemes, J. Escudié, I. Silaghi-Dumitrescu, H. Gornitzka, L. Silaghi-Dumitrescu and S. Massou, European Journal of Inorganic Chemistry, 2006, 2006, 4237.

14. T.-G. Kocsor, G. Nemes, N. Saffon, S. Mallet-Ladeira, D. Madec, A. Castel and J. Escudié, Dalton Trans., 2014, 43, 2718.

15. S. Ito, H. Miyake and M. Yoshifuji, Phosphorus, Sulfur and Silicon and the Related Elements, 2009, 184, 917.

16. J. Escudié, H. Ranaivonjatovo, M. Bouslikhane, Y. El Harouch, L. Baiget and G. Cretiu Nemes, Russian Chemical Bulletin, 2004, 53, 1020.

17. M. El Ezzi, R. Lenk, D. Madec, J.M. Sotiropoulos, S. Mallet-Ladeira and A. Castel, Angewandte Chemie - International Edition, 2015, 54, 805.

18. N. Deak, P.M. Petrar, S. Mallet-Ladeira, L. Silaghi-Dumitrescu, G. Nemeş and D. Madec, Chemistry - A European Journal, 2016, 22, 1349.

19. N. Deak, I.-T. Moraru, N. Saffon-Merceron, D. Madec and G. Nemes, European Journal of Inorganic Chemistry, 2017, 4214.

20. C. Overländer, J.J. Tirrée, M. Nieger, E. Niecke, C. Moser, S. Spirk and R. Pietschnig, Applied Organometallic Chemistry, 2007, 21, 46.

21. D.A. Atwood, A.H. Cowley and J. Ruiz, Inorganica Chimica Acta, 1992, 198200, 271.

22. O. Kühl, Phosphorus-31 NMR Spectroscopy, Springer Berlin Heidelberg, Berlin, Heidelberg, 2009.

23. A.N. Tavtorkin, S.A. Toloraya, E.E. Nifant'Ev and I.E. Nifant'Ev, Tetrahedron Letters, 2011, 52, 824.

24. L. Baiget, M. Bouslikhane, J. Escudie, G.C. Nemes, I. Silaghi-Dumitrescu and L. Silaghi-Dumitrescu, Phosphorus, Sulfur, and Silicon and the Related Elements, 2003, 178, 1949.

25. B. Buster, A.A. Diaz, T. Graham, R. Khan, M.A. Khan, D.R. Powell and R.J. Wehmschulte, Inorganica Chimica Acta, 2009, 362, 3465.

26. B. Cordero, V. Gómez, A.E. Platero-Prats, M. Revés, J. Echeverría, E. Cremades, F. Barragán and S. Alvarez, Dalton Transactions, 2008, 2832.

27. M. Mantina, A.C. Chamberlin, R. Valero, C.J. Cramer and D.G. Truhlar, The Journal of Physical Chemistry A, 2009, 113, 5806.

28. A. Bondi, The Journal of Physical Chemistry, 1964, 68, 441.

29. J. Bezombes, F. Carré, C. Chuit, R.J.P. Corriu, A. Mehdi and C. Reyé, Journal of Organometallic Chemistry, 1997, 535, 81. 
30. T. Řezníček, L. Dostál, A. Rưžička and R. Jambor, Journal of Organometallic Chemistry, 2012, 718, 38.

31. D.E. Herbert, A.D. Miller and O.V. Ozerov, Chemistry - A European Journal, 2012, 18, 7696.

32. T. Řezniček, L. Dostal, A. Růžička and R. Jambor, Main Group Metal Chemistry, 2012, 35, 129.

33. S. Ito, T. Nakagawa and K. Mikami, Chemical Communications, 2013, 49, 9221.

34. T.G. Kocsor, D. Matioszek, G. Nemeş, A. Castel, J. Escudié, P.M. Petrar, N. Saffon and I. Haiduc, Inorganic Chemistry, 2012, 51, 7782.

35. S. El Kettani, J. Escudie, C. Couret, H. Ranaivonjatovo, M. Lazraq, M. Soufiaoui, H. Gornitzka and G. Nemes, Chemical Communications, 2003, 1662.

36. SAINT and SADABS, Bruker AXS Inc., Madison, Wisconsin, USA.

37. G.M. Sheldrick, Acta Crystallographica, 2008, A64, 112.

38. G.M. Sheldrick, Acta Crystallographica, 2015, A71, 3. 